\title{
Distinct prognostic values and potential drug targets of ALDHI isoenzymes in non-small-cell lung cancer
}

This article was published in the following Dove Press journal:

Drug Design, Development and Therapy

3 September 2015

Number of times this article has been viewed

\section{Qinghua You' \\ Huanchen Guo ${ }^{2}$ \\ Dongxiang $\mathrm{Xu}^{3}$}

'Department of Pathology, Shanghai Pudong Hospital, Fudan University Pudong Medical Center, Shanghai, ${ }^{2}$ Department of Respiratory Medicine, Shouguang Hospital of Traditional Chinese Medicine, Shouguang, ${ }^{3}$ Department of Endocrinology, Shanghai Pudong Hospital, Fudan University Pudong Medical Center, Shanghai, People's Republic of China

Correspondence: Qinghua You Department of Pathology, Shanghai Pudong Hospital, Fudan University Pudong Medical Center, 2800 Gongwei Road, Huinan Town, Shanghai 201399, People's Republic of China Email qinghuayou0।@I63.com
Abstract: Increased aldehyde dehydrogenase 1 (ALDH1) activity has been found in the stem cell populations of leukemia and some solid tumors including non-small-cell lung cancer (NSCLC). However, which ALDH1's isoenzymes are contributing to ALDH1 activity remains elusive. In addition, the prognostic value of individual ALDH1 isoenzyme is not clear. In the current study, we investigated the prognostic value of ALDH1 isoenzymes in NSCLC patients through the Kaplan-Meier plotter database, which contains updated gene expression data and survival information from a total of 1,926 NSCLC patients. High expression of ALDH1A1 mRNA was found to be correlated to a better overall survival (OS) in all NSCLC patients followed for 20 years (hazard ratio [HR] 0.88 [0.77-0.99], $P=0.039$ ). In addition, high expression of $A L D H 1 A 1$ mRNA was also found to be correlated to better OS in adenocarcinoma (Ade) patients (HR 0.71 [0.57-0.9], $P=0.0044$ ) but not in squamous cell carcinoma (SCC) patients (HR 0.92 [0.72-1.16], $P=0.48$ ). High expression of $A L D H 1 A 2$ and $A L D H 1 B 1$ mRNA was found to be correlated to worser OS in all NSCLC patients, as well as in Ade, but not in SCC patients. High expression of both ALDH1A3 and ALDH1L1 mRNA was not found to be correlated to OS in all NSCLC patients. These results strongly support that ALDH1A1 mRNA in NSCLC is associated with better prognosis. In addition, our current study also supports that ALDH1A2 and ALDH1B1 might be major contributors to the ALDH1 activity in NSCLC, since high expression of $A L D H 1 A 2$ and $A L D H 1 B 1$ mRNA was found to be significantly correlated to worser OS in all NSCLC patients. Based on our study, ALDH1A2 and ALDH1B1 might be excellent potential drug targets for NSCLC patients.

Keywords: NSCLC, ALDH1, cancer stem cell, prognosis, drug target, KM plotter, hazard ratio

\section{Introduction}

Non-small-cell lung cancer (NSCLC) includes the following major histological types: adenocarcinoma (Ade) and squamous cell carcinoma (SCC). NSCLC accounts for approximately $85 \%$ of all lung cancers, which makes NSCLC the leading cause of cancer-related deaths worldwide. ${ }^{1,2}$ Despite the advances in early detection, radical cure operation, and multimodal therapeutic modalities, at diagnosis, there are approximately $80 \%$ of NSCLC cases in advanced stage. The incidence of NSCLC is still increasing, and systemic chemotherapy that remains in the standard care only provides marginal improvement in survival. ${ }^{3}$ Therefore, further investigation on the mechanism of initiation, progression, and identification of prognostic markers and potential drug targets is still needed and will help select the patients with higher chance of lung cancer recurrence in order to provide better prognosis and individualized treatment. 
Aldehyde dehydrogenase 1 (ALDH1) family is composed of enzymes that are expressed at high levels in stem cells (SCs) and contributes to the oxidation of retinol to retinoic acid in SC differentiation. ${ }^{4-6}$ Elevated ALDH1 activity has been detected in the SC populations of human acute myeloid leukemia, multiple myeloma, and a number of solid tumors. ${ }^{7-11}$ Therefore, examination of ALDH1 activity might be used as a common marker for both normal and malignant SC populations. Increased ALDH1 expression has been reported in some lung cancer cell lines, malignant transformation of lung cells, ${ }^{12,13}$ and lung tissues. ${ }^{14}$ However, which ALDH1's isoenzymes are contributing to ALDH1 activity in NSCLC has not been determined. In addition, the prognostic value of individual ALDH1 isoenzyme in NSCLC remains elusive. The "Kaplan-Meier plotter" (KM plotter) generated data from Gene Expression Omnibus (GEO; www. ncbi.nlm.nih.gov/geo/) database. KM plotter database was initially established using data on expression manifested by 22,277 genes in a group of 1,809 breast cancer patients. ${ }^{15,16}$ Later, this database also included gene expression data and survival information from a total of 1,715 NSCLC patients. ${ }^{17}$ Currently, they increased the patient number to a total of 1,926 . Thus, KM plotter can be utilized for the analysis of individual genes with clinical results to relapse-free survival and total survival of the patients. So far, a number of genes have been identified and/or validated by KM plotter in breast cancer $^{18-26}$ as well as in NSCLC..$^{27}$ In this study, we determined the prognostic value of individual ALDH1 isoenzymes in human NSCLC patients using KM plotter database.

\section{Materials and methods}

We used an online database ${ }^{15}$ to determine the relevance of individual $A L D H 1$ members' mRNA expression to relapse-free survival. Currently, they have breast cancer, ${ }^{15}$ lung cancer, ${ }^{17}$ ovarian cancer, ${ }^{28}$ and gastric cancer database. NSCLC patients in the database were identified from Cancer
Biomedical Informatics Grid (http://cabig.cancer.gov/, microarray samples are published in the caArray project), the GEO (www.ncbi.nlm.nih.gov/geo/), and The Cancer Genome Atlas (TCGA; http://cancergenome.nih.gov) lung cancer datasets. ${ }^{17}$ They collected clinical data including only age, sex, smoking history, histology, stage, grade, success of surgery, radiotherapy, and applied chemotherapy for all patients in WinStat 2013. The database was established using gene expression data and survival information of 1,926 NSCLC patients downloaded from GEO. Briefly, five $A L D H 1$ submembers (ALDH1A1, ALDH1A2, ALDH1A3, ALDH1B1, and $A L D H 1 L 1)$ were entered into the database (http://kmplot.

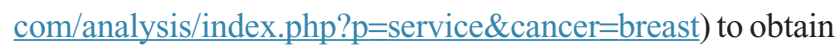
Kaplan-Meier survival plots in which the number at risk is indicated below the main plot. Hazard ratio (HR; and 95\% confidence intervals) and log rank $P$ were calculated and displayed on the webpage.

\section{Results}

The ALDH1 family is composed of six sub-members, and their characteristics are shown in Table 1. As previously indicated, ${ }^{26}$ among all the six ALDH1 isoenzymes, only $A L D H 1 L 2$ was not found in www.kmplot.com, probably due to its low expression.

We first examined the prognostic value of ALDH1A1 mRNA expression in www.kmplot.com. The desired Affymetrix ID is valid: 212224_at (ALDH1A1). Survival curves are plotted for all patients $(\mathrm{n}=1,926)$ (Figure 1A), for Ade $(\mathrm{n}=719)$ (Figure 1B), and for SCC $(\mathrm{n}=525)$ (Figure 1C). High expression of ALDH1A1 mRNA was found to be correlated to better overall survival (OS) in all NSCLC patients followed for 20 years (HR 0.88 [0.77-0.99], $P=0.039$ ). In addition, high expression of ALDH1A1 mRNA was also found to be correlated to better OS in Ade patients (HR 0.71 [0.57-0.9], $P=0.0044$ ) but not in SCC patients (HR 0.92 [0.72-1.16], $P=0.48)$.

Table I Alternatively spliced variants and characterization of ALDHI isoenzymes

\begin{tabular}{|c|c|c|c|c|}
\hline Isoenzymes & Alternatively spliced variants & Cellular localization & Tissue distribution & Associated diseases \\
\hline ALDHIAI & ALDHIAI_v2 & Cytosol & $\begin{array}{l}\text { Lung, breast, brain, pancreas, } \\
\text { liver, kidney, etc }\end{array}$ & Alcoholism \\
\hline ALDHIA2 & $\begin{array}{l}\text { ALDHIA2_v2, ALDHIA2_v3, } \\
\text { ALDHIA2_v4 }\end{array}$ & Cytosol & Kidney, testis, liver & Schizophrenia, spina bifida \\
\hline ALDHIA3 & ALDHIA3_v2 & Cytosol & $\begin{array}{l}\text { Skeletal muscle, lung, breast, } \\
\text { kidney, etc }\end{array}$ & $\begin{array}{l}\text { Autosomal recessive } \\
\text { anophthalmia/microphthalmia }\end{array}$ \\
\hline ALDHIBI & $\mathrm{N} / \mathrm{A}$ & Mitochondria & $\begin{array}{l}\text { Liver, heart, kidney, } \\
\text { brain, prostate }\end{array}$ & $N / A$ \\
\hline ALDHILI & $\mathrm{N} / \mathrm{A}$ & Cytosol & Kidney, liver, skeletal muscle & Ischemic stroke \\
\hline ALDHIL2 & ALDHIL2_v2, ALDHIL2_v2 & Mitochondria & Pancreas, heart, and brain & $N / A$ \\
\hline
\end{tabular}

Abbreviations: ALDHI, aldehyde dehydrogenase I; N/A, not available. 
A

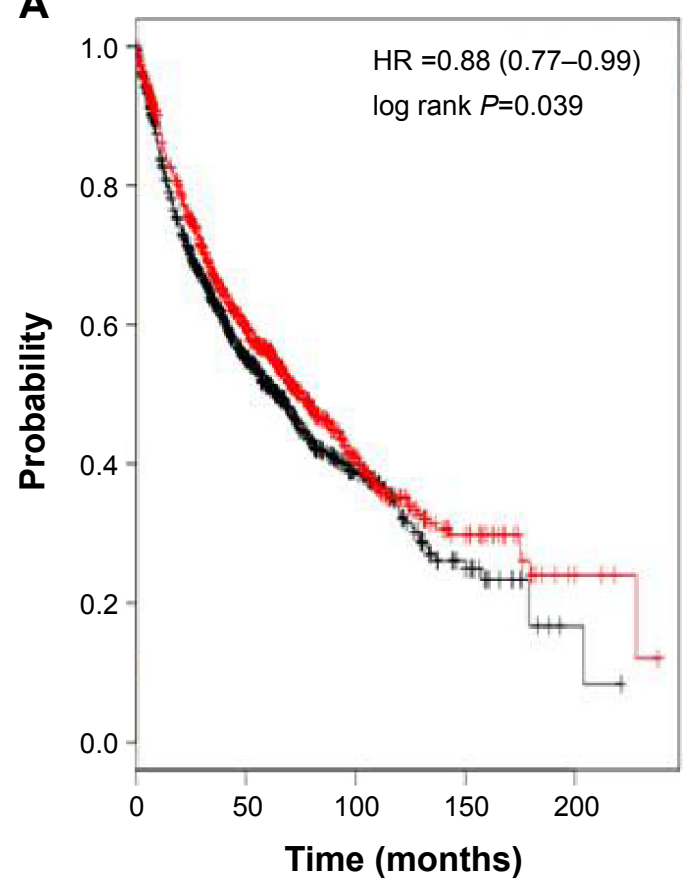

B

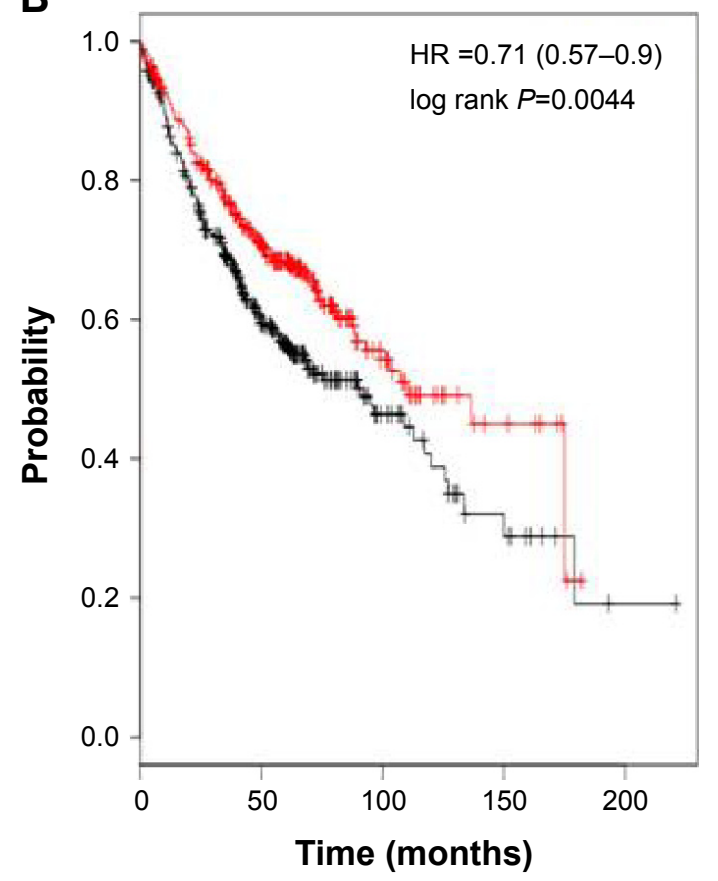

\section{Number at risk}

$\begin{array}{lllll}\text { Low } 963 & 384 & 90 & 23 & 2\end{array}$
Number at risk

$\begin{array}{lllll}\text { Low } 360 & 152 & 31 & 10 & 1 \\ \text { High } 359 & 195 & 38 & 9 & 0\end{array}$

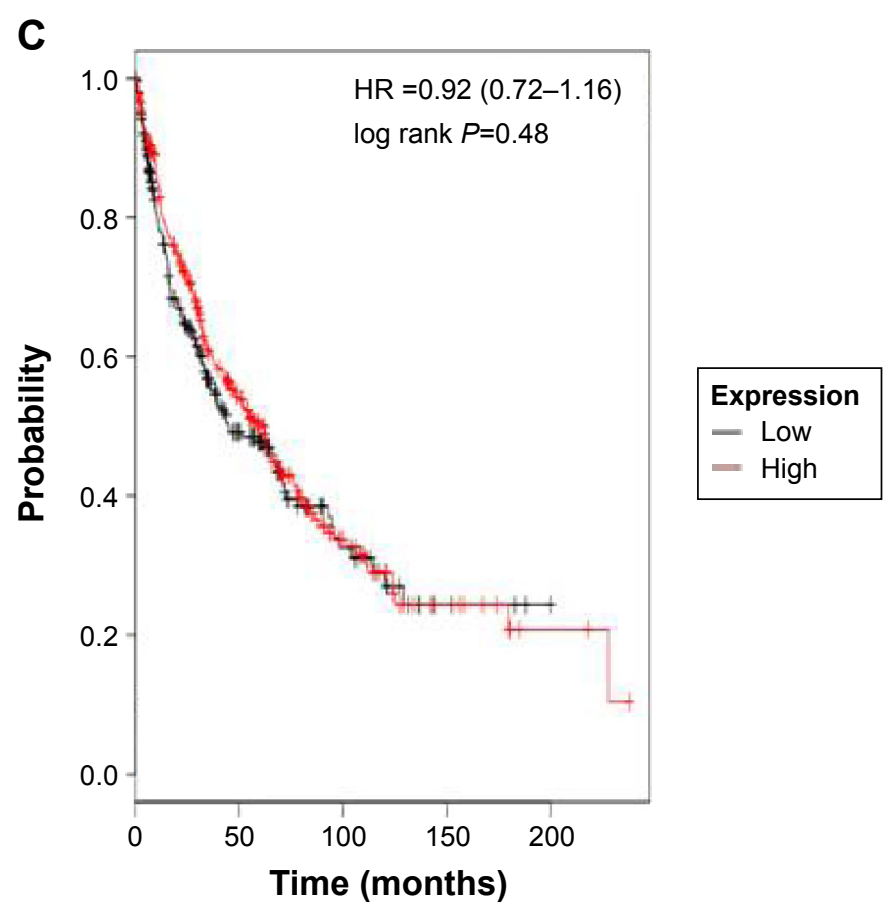

Number at risk

\begin{tabular}{|c|c|c|c|}
\hline Low 262 & 75 & 22 & 4 \\
\hline High 263 & 105 & 32 & 11 \\
\hline
\end{tabular}

Figure I The prognostic value of ALDHIAI expression.

Notes: The desired Affymetrix ID is valid: 2I2224_at (ALDHIAI). (A) Survival curves are plotted for all patients ( $\mathrm{n}=\mathrm{I}, 926)$. (B) Survival curves are plotted for adenocarcinoma $(n=719)$. (C) Survival curves are plotted for squamous cell carcinoma $(n=525)$. Data was analyzed using Kaplan Meier Plotter (www.kmplot.com). Abbreviation: $\mathrm{HR}$, hazard ratio. 
We then examined the prognostic value of $A L D H 1 A 2$ mRNA expression in www.kmplot.com. The desired Affymetrix ID is valid: 207015_s_at (ALDH1A2). High expression of $A L D H 1 A 2$ mRNA was found to be correlated to worser OS in all NSCLC patients (HR 1.24 [1.09-1.4], $P=0.00093$ ) (Figure 2A). In addition, high expression of ALDH1A2 mRNA was also found to be correlated to worser OS in Ade patients (HR 1.57 [1.24-1.98], $P=0.00015$ ) (Figure 2B) but not in SCC patients (HR 1.14 [0.9-1.44], $P=0.29$ ) (Figure 2C).

Figure 3 shows the prognostic value of $A L D H 1 A 3$ mRNA expression in www.kmplot.com. The desired Affymetrix ID is valid: 203180_at (ALDH1A3). The curves show that ALDH1A3 expression above or below the median does not separate the cases into significantly different prognostic groups in NSCLC patients (HR 0.99 [0.88-1.13], $P=0.94$ ) (Figure 3A) or Ade patients (HR 0.97 [0.77-1.22], $P=0.79$ ) (Figure 3B), or SCC patients (HR 1.04 [0.82-1.31], $P=0.77$ ) (Figure 3C).

Figure 4 shows the prognostic value of $A L D H 1 B 1 \mathrm{mRNA}$ expression in www.kmplot.com. The desired Affymetrix ID is valid: 209646_x_at (ALDH1B1). High expression of $A L D H 1 B 1$ mRNA was found to be correlated to worser OS in all NSCLC patients (HR 1.53 [1.35-1.74], $P=4.5 \mathrm{e}-11$ ) (Figure 4A). In addition, high expression of $A L D H 1 B 1$ mRNA was also found to be correlated to worser OS in Ade patients (HR 2.03 [1.6-2.59], $P=5.2 \mathrm{e}-09$ ) (Figure 4B) but not in SCC patients (HR 1.07 [0.85-1.36], $P=0.57$ ) (Figure 4C).

Finally, we examined the prognostic value of $A L D H 1 L 1$ mRNA expression in www.kmplot.com. The desired Affymetrix ID is valid: 205208_at ( $A L D H 1 L 1)$. The curves show that $A L D H 1 L 1$ expression above or below the median does not separate the cases into significantly different prognostic groups in NSCLC patients (HR 1.1 [0.97-1.25], $P=0.13$ ) (Figure 5A) or Ade patients (HR 1.19 [0.94-1.5], $P=0.14$ ) (Figure 5B), or SCC patients (HR 0.87 [0.69-1.1], $P=0.26$ ) (Figure 5C).

To further determine the correlation of individual ALDH1 isoenzymes with other clinicopathological features, we examined the correlation with smoking status (Table 2), clinical stages (Table 3), and chemotherapy (Table 4) of NSCLC patients. As shown in Table 2, all the individual ALDH1s except ALDH1A3 are significantly associated with smoking status of NSCLC patients. As shown in Table 3, all the individual ALDH1s except ALDH1A1 are significantly associated with clinical stages of NSCLC patients. As shown in Table 4, only ALDH1L1 is significantly associated with chemotherapy of NSCLC patients, probably due to relatively limited number of patients.

\section{Discussion}

Normal SCs are considered to have ability to undergo selfrenewal and multilineage differentiation. ${ }^{29}$ Accumulating evidence has proposed a model in which tumorigenesis is driven by cancer stem cells (CSCs) that are derived from mutated adult SCs. ${ }^{30} \mathrm{CSC}$ s initiate and drive carcinogenesis and differentiation through the deregulation of the selfrenewal process, contribute to tumor cellular heterogeneity, develop into phenotypically diverse cancer cell populations, proliferate extensively, and drive both continuous expansion of malignant cells and resistance to chemotherapy; thus, CSCs represent the apex in the hierarchical model of tumor genesis, heterogeneity, and metastasis. ${ }^{31-33}$ Many human cancers including NSCLC possess an enhanced tumor-initiating capacity and partially recreate the cellular heterogeneity of the parental tumor. Previous studies have identified CSCs as responsible risk factors for tumor initiation, growth, and metastasis in solid tumors. ${ }^{34,35}$

ALDH1 belongs to a family of detoxifying enzymes that convert aldehydes to their corresponding carboxylic acids, and members of this family are present in many types of normal tissues. ${ }^{36,37}$ Currently, the "gold standard" of the measurement of the activity of ALDH1 in viable cells has been the use of flow cytometry and fluorescent substrates for ALDH1. ${ }^{10,38,39}$ Jiang et al first observed that the ALDH1-positive lung cancer cells exhibited the important CSC properties: in vitro self-renewal, differentiation, and multidrug resistance capacities, expression of SC marker, in vivo tumor initiation, and occurrence of a heterogeneous population of cancer cells. ${ }^{14}$ They also found that relatively high ALDH1 protein levels were positively associated with stage and grade of the tumors and inversely related to the patients' survival, and their data suggested that ALDH1 might be a lung tumor SC marker and a potential prognostic factor and a therapeutic target for efficient treatment of lung cancer. ${ }^{14}$ A multivariate analysis also identified ALDH1 expression in NSCLC as significantly independent prognostic factors for disease-free survival $(P=0.045)$ and indicated that the immunophenotypes of ALDH1 in cancer cells could have prognostic value in patients with NSCLC who are treated with neoadjuvant therapy ${ }^{40}$ However, an exploratory and retrospective study in NSCLC indicates that, unlike breast cancer in which ALDH1 expression predicts poor outcome, ALDH1 expression is associated with favorable outcome. ${ }^{41}$ The prognostic value of ALDH1 isoenzyme mRNA in NSCLC patients was not reported. Using KM plotter, we found that high expression of ALDH1A1 mRNA was correlated to better OS in all NSCLC patients. In addition, high expression of ALDH1A1 mRNA 
A

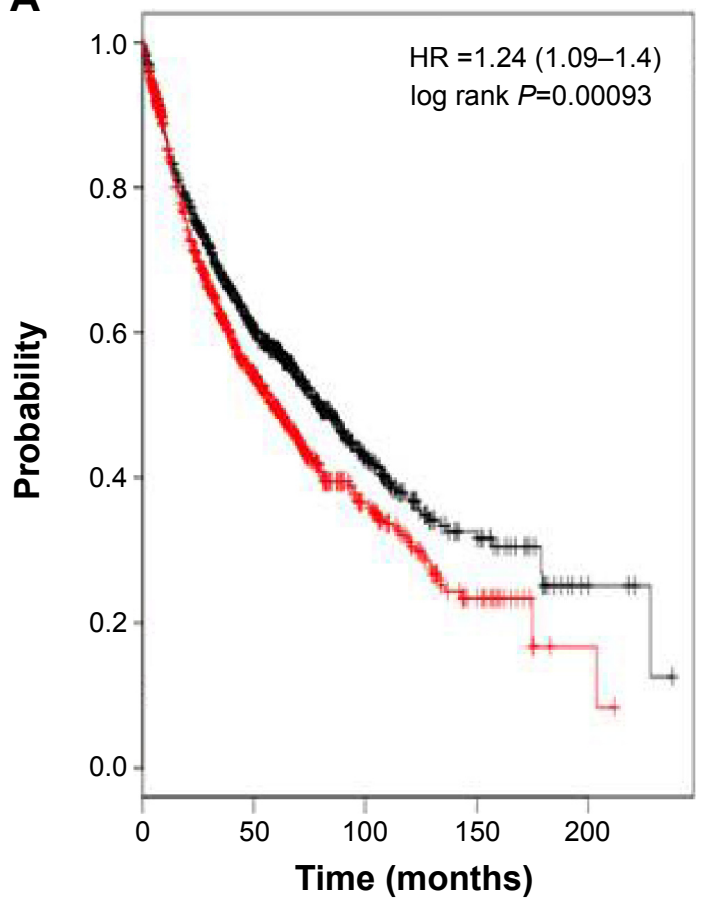

\section{B}

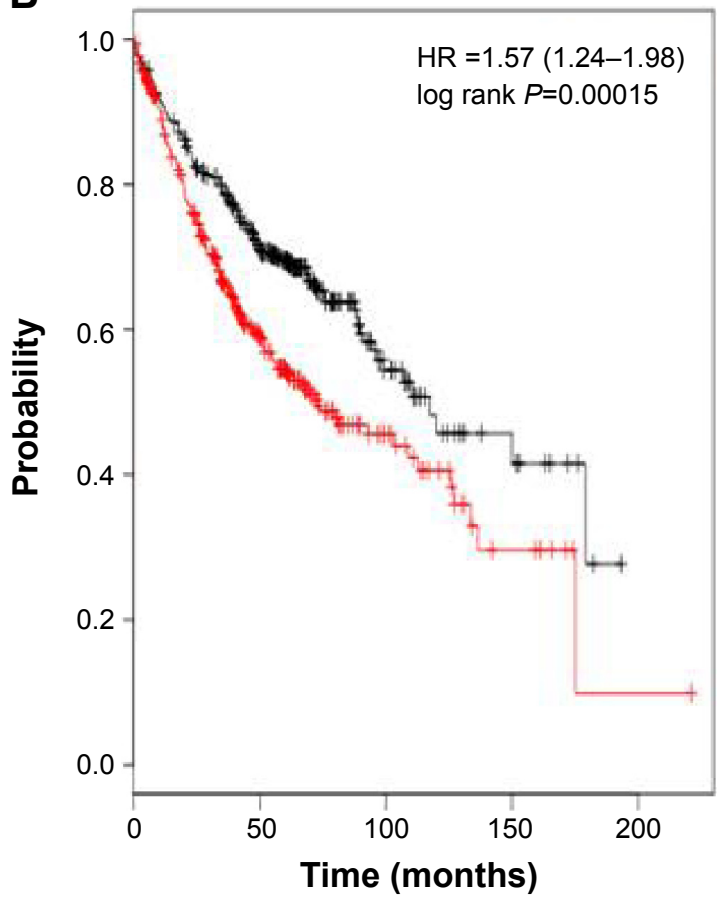

Number at risk

$\begin{array}{lllll}\text { Low } 364 & 210 & 38 & 11 & 0 \\ \text { High } 355 & 137 & 31 & 8 & 1\end{array}$

$\begin{array}{lllll}\text { Low } 990 & 463 & 110 & 35 & 5 \\ \text { High } 936 & 365 & 93 & 22 & 2\end{array}$

C

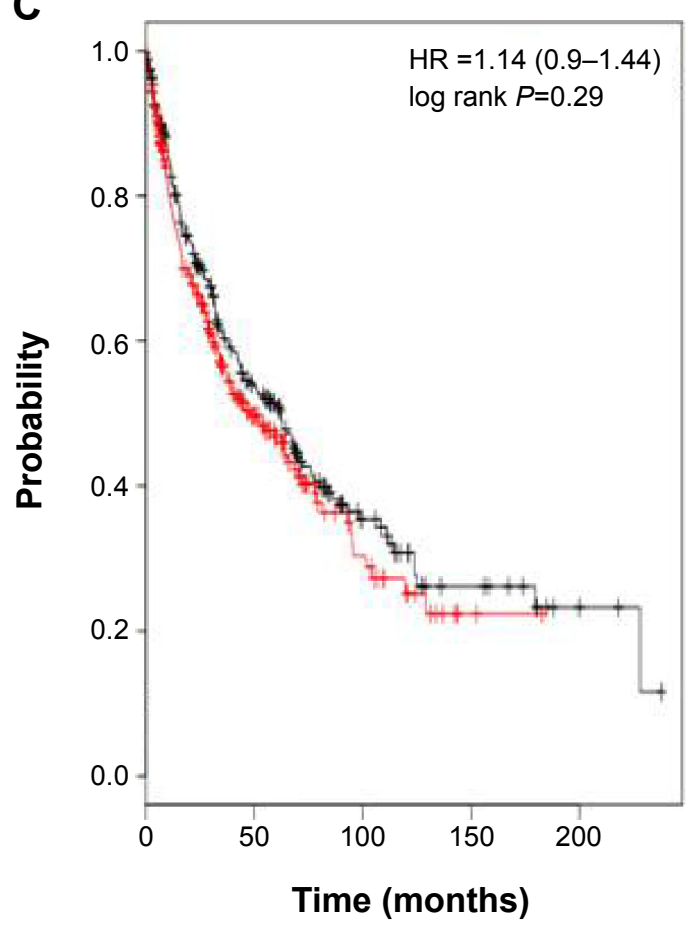

Expression
- Low
- High

Number at risk

$\begin{array}{ccccc}\text { Low } 266 & 104 & 34 & 13 & 4 \\ \text { High } 259 & 76 & 20 & 2 & 0\end{array}$

Figure 2 The prognostic value of ALDHIA2 expression.

Notes: The desired Affymetrix ID is valid: 2070I5_s_at (ALDHIA2). (A) Survival curves are plotted for all patients ( $\mathrm{n}=1,926)$. (B) Survival curves are plotted for adenocarcinoma $(n=719)$. (C) Survival curves are plotted for squamous cell carcinoma $(n=525)$. Data was analyzed using Kaplan Meier Plotter (www.kmplot.com). Abbreviation: HR, hazard ratio. 


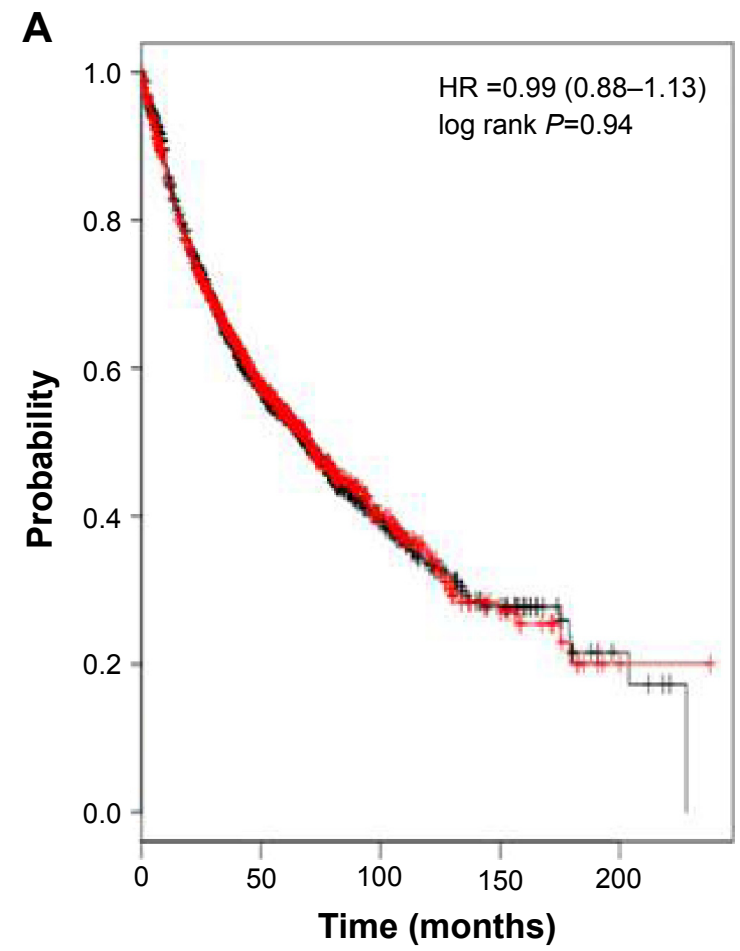

Number at risk

$\begin{array}{lllll}\text { Low } 963 & 415 & 113 & 35 & 5 \\ \text { High } 963 & 413 & 90 & 22 & 5\end{array}$

\section{B}

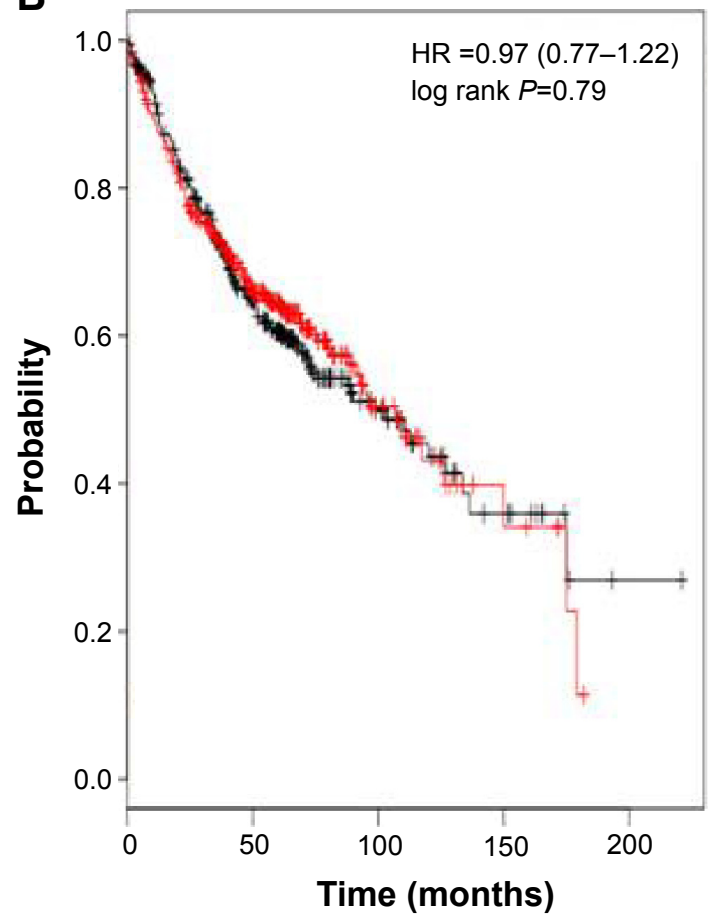

Number at risk

$\begin{array}{ccccc}\text { Low } 360 & 171 & 41 & 12 & 1 \\ \text { High } 359 & 176 & 28 & 7 & 0\end{array}$

C

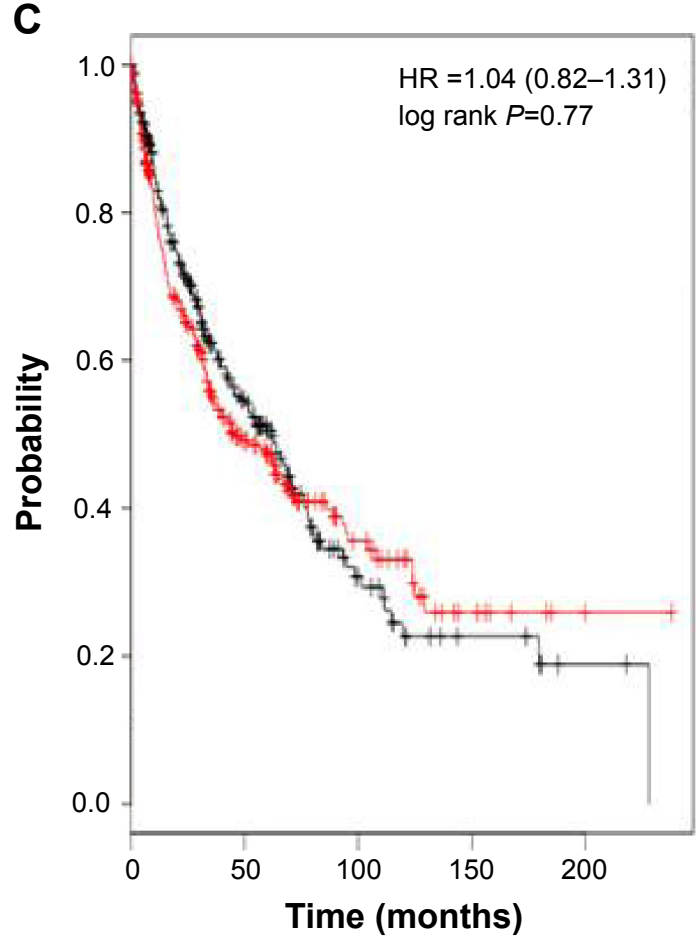

Expression

- Low

- High

Number at risk

$\begin{array}{llllll}\text { Low } & 262 & 94 & 23 & 7 & 2 \\ \text { High } 263 & 86 & 31 & 8 & 2\end{array}$

Figure 3 The prognostic value of ALDHIA3 expression.

Notes: The desired Affymetrix ID is valid: 203180 at (ALDHIA3). (A) Survival curves are plotted for all patients ( $\mathrm{n}=1,926)$. (B) Survival curves are plotted for adenocarcinoma $(n=719)$. (C) Survival curves are plotted for squamous cell carcinoma $(n=525)$. Data was analyzed using Kaplan Meier Plotter (www.kmplot.com).

Abbreviation: HR, hazard ratio. 
A

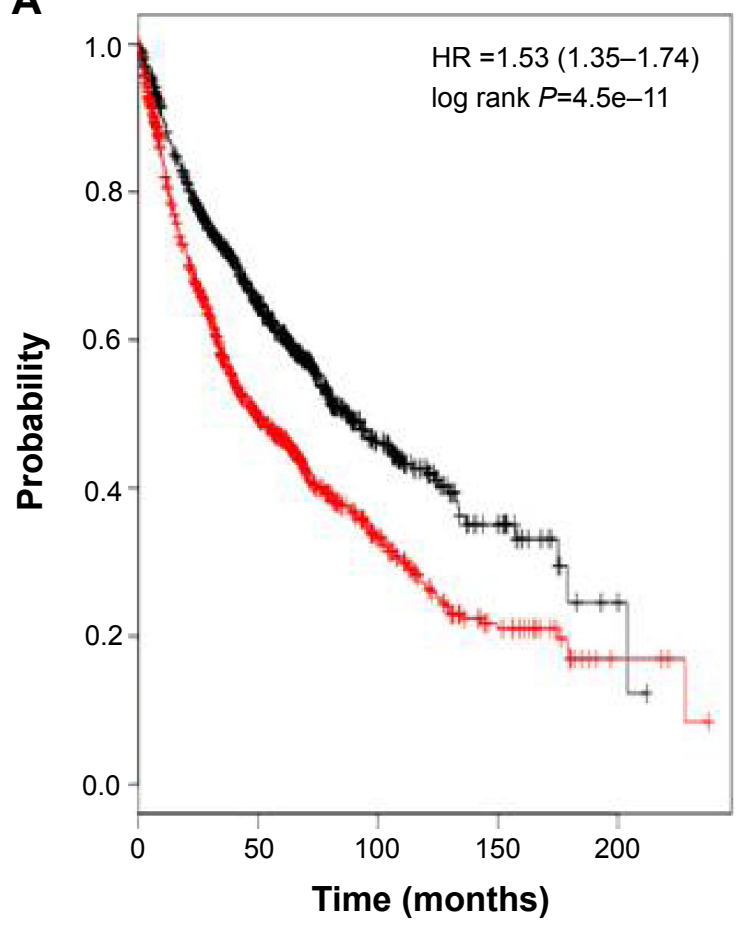

Number at risk

$\begin{array}{lllll}\text { Low } 972 & 473 & 105 & 26 & 3 \\ \text { High } 954 & 355 & 98 & 31 & 4\end{array}$

B

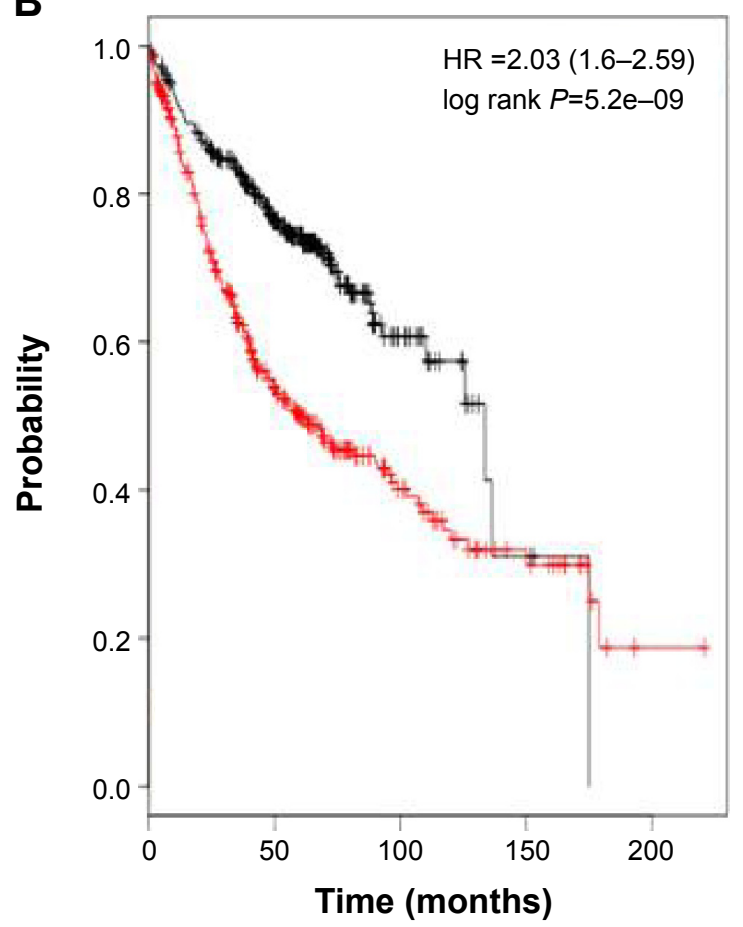

Number at risk

$\begin{array}{lllll}\text { Low } 360 & 204 & 28 & 3 & 0\end{array}$

C

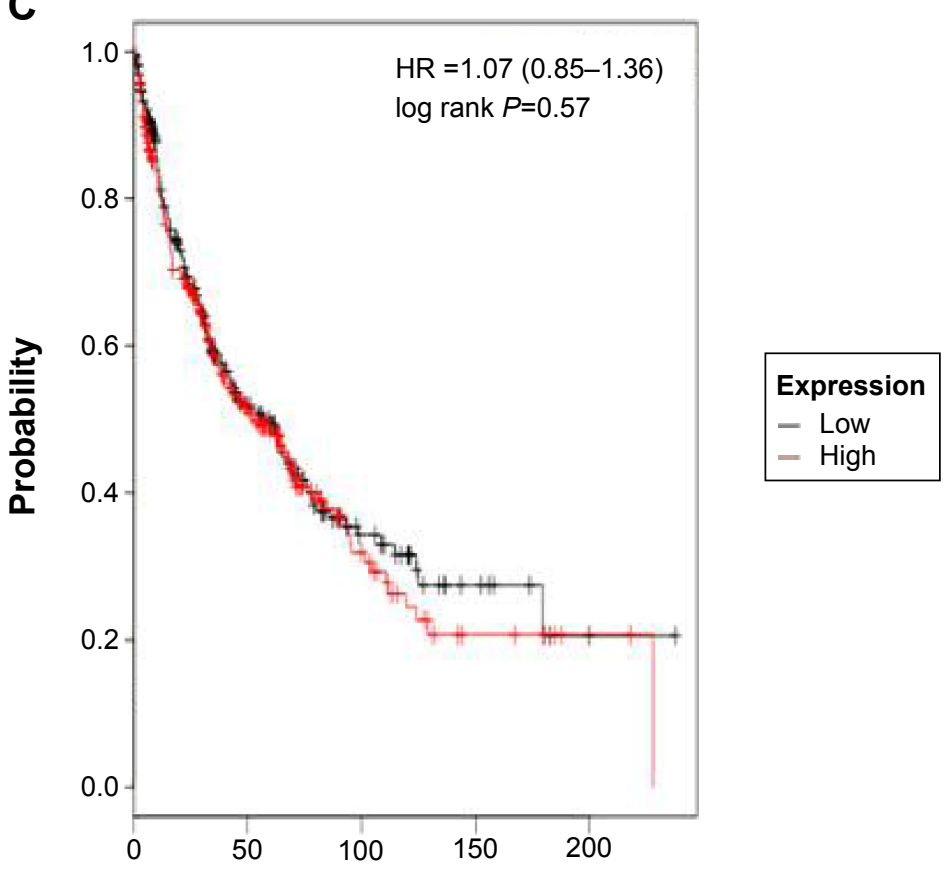

Time (months)

Number at risk

$\begin{array}{llllll}\text { Low } & 263 & 83 & 28 & 8 & 2 \\ \text { High } & 262 & 97 & 26 & 7 & 2\end{array}$

Figure 4 The prognostic value of ALDHIBI expression.

Notes: The desired Affymetrix ID is valid: 209646_x at (ALDHIBI). (A) Survival curves are plotted for all patients ( $\mathrm{n}=1,926)$. (B) Survival curves are plotted for

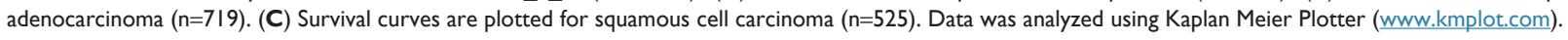
Abbreviation: $\mathrm{HR}$, hazard ratio. 
A

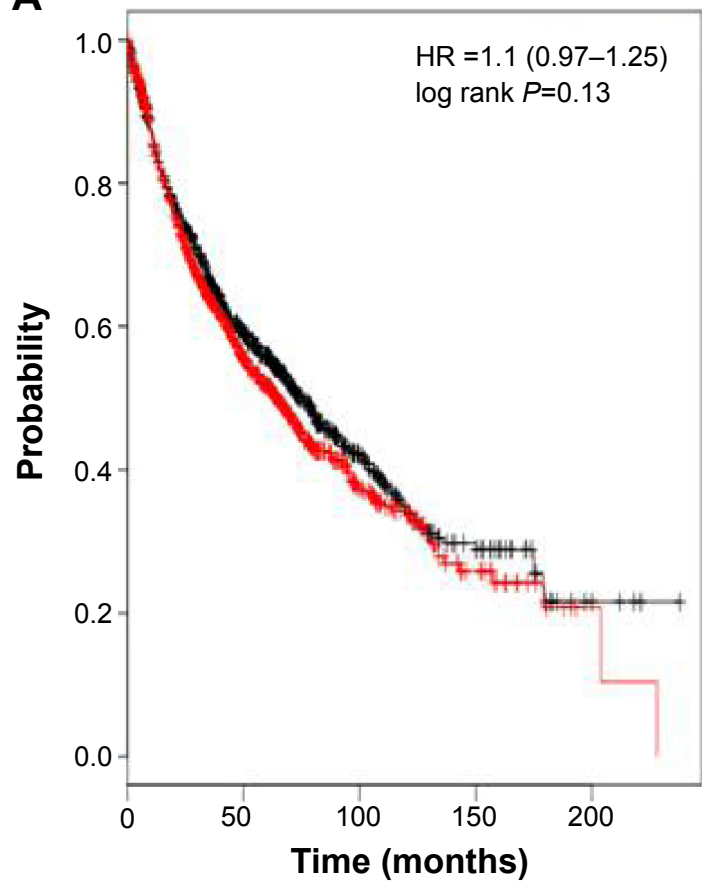

Number at risk

$\begin{array}{llllll}\text { Low } & 965 & 442 & 117 & 36 & 5\end{array}$

\section{B}

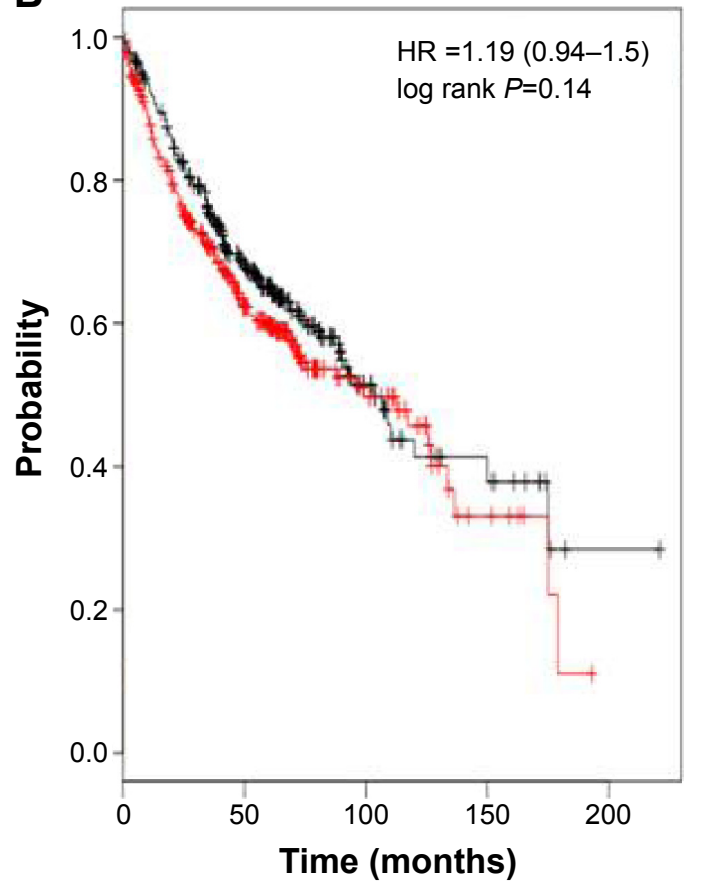

Number at risk

$\begin{array}{lllll}\text { Low 360 } & 188 & 34 & 12 & 1 \\ \text { High 359 } & 159 & 35 & 7 & 0\end{array}$

C

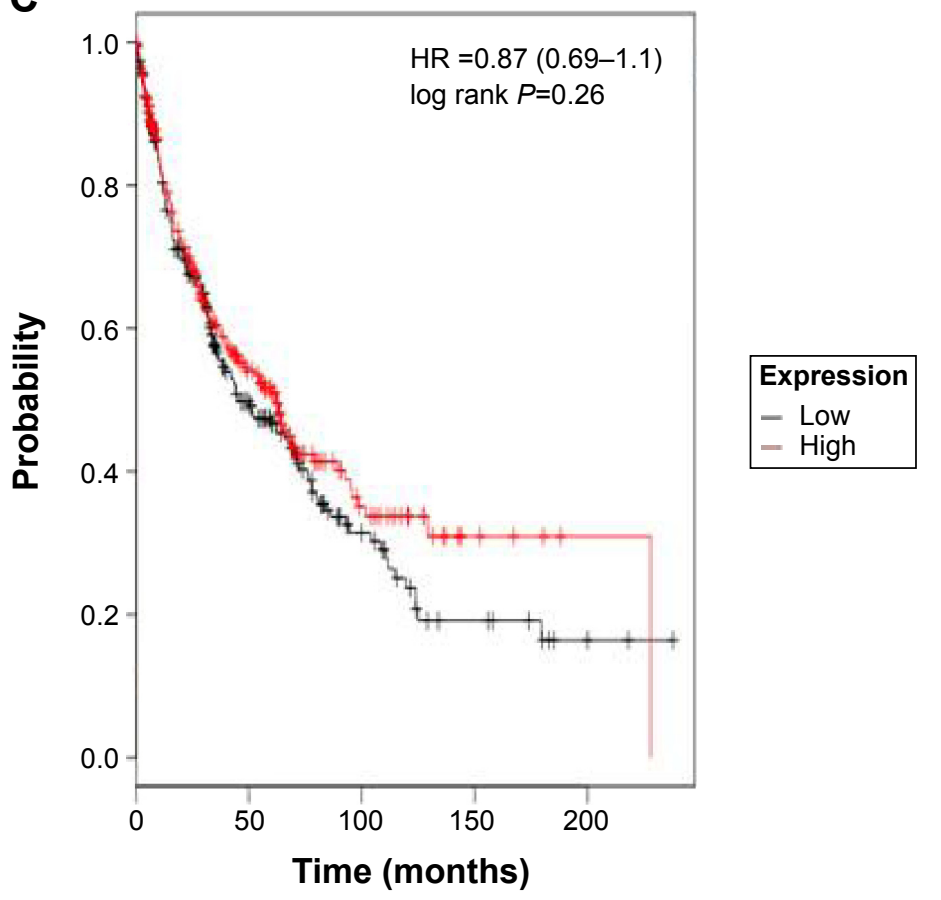

Number at risk

$\begin{array}{llllll}\text { Low } & 263 & 86 & 28 & 10 & 3\end{array}$

Figure 5 The prognostic value of ALDHILI expression.

Notes: The desired Affymetrix ID is valid: 205208_at (ALDHILI). (A) Survival curves are plotted for all patients $(\mathrm{n}=\mathrm{I}, 926)$. (B) Survival curves are plotted for adenocarcinoma $(n=7 \mid 9)$. (C) Survival curves are plotted for squamous cell carcinoma $(n=525)$. Data was analyzed using Kaplan Meier Plotter (www.kmplot.com).

Abbreviation: HR, hazard ratio. 
Table 2 Correlation of ALDHI isoenzymes with smoking status of NSCLC patients

\begin{tabular}{llllll}
\hline Isoenzymes & Smoking status & Cases & HR & 95\% Cl & P-value \\
\hline ALDHIAI & Never smoked & 205 & 0.57 & $0.32-1$ & 0.049 \\
& Smoked & $82 I$ & 0.85 & $0.69-1.05$ & 0.13 \\
ALDHIA2 & Never smoked & 205 & 2.09 & $1.17-3.72$ & 0.011 \\
& Smoked & 821 & 1.32 & $1.07-1.63$ & 0.0088 \\
ALDHIA3 & Never smoked & 205 & 0.76 & $0.43-1.33$ & 0.33 \\
& Smoked & 821 & 0.99 & $0.81-1.22$ & 0.94 \\
ALDHIBI & Never smoked & 205 & 4.64 & $2.37-9.07$ & $7.9 \mathrm{e}-07$ \\
& Smoked & 821 & 1.24 & $1.01-1.52$ & 0.043 \\
ALDHILI & Never smoked & 205 & 2.19 & $1.22-3.94$ & 0.0073 \\
& Smoked & 821 & 1.16 & $0.94-1.43$ & 0.16 \\
\hline
\end{tabular}

Abbreviations: ALDHI, aldehyde dehydrogenase I; NSCLC, non-small-cell lung cancer; $\mathrm{HR}$, hazard ratio; $\mathrm{Cl}$, confidence interval.

was also found to be correlated to better OS in Ade patients (HR 0.71 [0.57-0.9], $P=0.0044$ ) but not in SCC patients (HR 0.92 [0.72-1.16], $P=0.48$ ). High expression of $A L D H 1 A 2$ and $A L D H 1 B 1 \mathrm{mRNA}$ was found to be correlated to worser OS in all NSCLC patients, as well as in Ade, but not in SCC patients. High expression of both ALDH1A3 and ALDH1L1 mRNA was not found to be correlated to OS in all NSCLC patients. Real-time polymerase chain reaction performed on an array of human tissues has shown that ALDH1L2 is expressed in the liver, kidney, pancreas, heart, and brain; no information is available on its expression in lung tissue. ${ }^{42}$ No survival information on ALDH1L2 in NSCLC patients is available, probably due to its low expression in lung tissue and NSCLC.

Previous studies have focused on the relationship between the expression of ALDH1A1 protein and the

Table 3 Correlation of ALDHI isoenzymes with clinical stages of NSCLC patients

\begin{tabular}{llllll}
\hline Isoenzymes & Clinical stages & Cases & HR & $95 \% \mathbf{C l}$ & P-value \\
\hline ALDHIAI & I & 578 & 0.9 & $0.69-1.18$ & 0.44 \\
& II & 244 & I & $0.7-1.45$ & 0.98 \\
& III & 70 & 0.99 & $0.57-1.72$ & 0.97 \\
ALDHIA2 & I & 578 & 1.52 & $1.16-1.99$ & 0.0023 \\
& II & 244 & 1.58 & $1.1-2.28$ & 0.013 \\
& III & 70 & 0.78 & $0.45-1.35$ & 0.38 \\
ALDHIA3 & I & 578 & 0.79 & $0.6-1.04$ & 0.09 \\
& II & 244 & 0.72 & $0.5-1.04$ & 0.078 \\
& III & 70 & 1.79 & $1.04-3.09$ & 0.034 \\
ALDHIBI & I & 578 & 2.41 & $1.81-3.21$ & $6.4 \mathrm{e}-10$ \\
& II & 244 & 1.28 & $0.89-1.86$ & 0.18 \\
& III & 70 & 1.02 & $0.59-1.76$ & 0.93 \\
ALDHILI & I & 578 & 1.07 & $0.81-1.39$ & 0.64 \\
& II & 244 & 1.53 & $1.06-2.21$ & 0.021 \\
& III & 70 & 0.89 & $0.52-1.53$ & 0.68 \\
\hline
\end{tabular}

Abbreviations: ALDHI, aldehyde dehydrogenase I; NSCLC, non-small-cell lung cancer; $\mathrm{HR}$, hazard ratio; $\mathrm{Cl}$, confidence interval.
Table 4 Correlation of ALDHI isoenzymes with chemotherapy of NSCLC patients

\begin{tabular}{llllll}
\hline Isoenzymes & Chemotherapy & Cases & HR & 95\% CI & P-value \\
\hline ALDHIAI & No & 310 & 0.9 & $0.69-1.18$ & 0.44 \\
& Yes & 176 & 0.75 & $0.53-1.04$ & 0.086 \\
ALDHIA2 & No & 310 & 1.08 & $0.77-1.5$ & 0.67 \\
& Yes & 176 & 0.78 & $0.52-1.17$ & 0.23 \\
ALDHIA3 & No & 310 & 1.18 & $0.85-1.65$ & 0.32 \\
& Yes & 176 & 1.08 & $0.72-1.63$ & 0.71 \\
ALDHIBI & No & 310 & 1.18 & $0.85-1.65$ & 0.33 \\
& Yes & 176 & 1.13 & $0.75-1.7$ & 0.55 \\
ALDHILI & No & 310 & 1.46 & $1.04-2.04$ & 0.028 \\
& Yes & 176 & 0.97 & $0.65-1.46$ & 0.9 \\
\hline
\end{tabular}

Abbreviations: ALDHI, aldehyde dehydrogenase I; NSCLC, non-small-cell lung cancer; $\mathrm{HR}$, hazard ratio; $\mathrm{Cl}$, confidence interval.

clinicopathologic parameters, including prognosis of tumor patients. In most types of tumors, such as breast cancer, ${ }^{10,43,44}$ colorectal carcinoma ${ }^{45}$ esophageal SCC ${ }^{46}$ clear cell renal cell carcinoma, ${ }^{47}$ gastric cancer ${ }^{48} \mathrm{SCC}$ of the head and neck, ${ }^{49}$ and urothelial carcinomas of urinary bladder, ${ }^{50}$ high expression of ALDH1A1 protein was associated with tumor metastasis and poor prognosis. In contrast to earlier studies, there was also evidence of ALDH1A1 as a marker of astrocytic differentiation during brain development and of better prognosis in patients suffering from primary glioblastoma. ${ }^{51}$ Jiang et al reported that isolated lung cancer cells with relatively high ALDH1 activity display in vitro features of CSCs, including capacities for proliferation, self-renewal, and differentiation, resistance to chemotherapy, and expression of CSC surface marker CD133. ${ }^{14}$ The ALDH1-positive cells could generate tumors, and expression of ALDH1 is positively correlated to the stage and grade of lung tumors and related to a poor prognosis in the patients with early-stage lung cancer. In another report, the enzymatic activity of human ALDH1A2 and ALDH2 in lung cancer cells is detected by Aldefluor and inhibited by diethylaminobenzaldehyde and has significant effects on cell proliferation and drug resistance.$^{52}$ However, Shao et al showed that ALDH1A3 is the predominant ALDH isoenzyme responsible for ALDH1 activity and tumorigenicity in most NSCLCs, and that inhibiting either ALDH1A3 or the signal transducer and activator of transcription (STAT) 3 pathway is the potential therapeutic strategy to eliminate the ALDH(+) subpopulation in NSCLCs.${ }^{53}$ Our current study found that unlike breast cancer, $A L D H 1 A 1$ mRNA in NSCLC is associated with better prognosis. In addition, our current study also supports that ALDH1A2 and ALDH1B1 might be major contributors to the ALDH1 activity in NSCLC, since high expression of $A L D H 1 A 2$ and $A L D H 1 B 1$ 
mRNA was found to be significantly correlated to worser OS in all NSCLC patients. Since high-quality commercial antibodies against ALDH1A1 are already available, the analysis of ALDH1A1 expression by immunohistochemistry will also be important for the design of treatment and the assessment of the prognosis of NSCLC patients. Based on our study, ALDH1A2 and ALDH1B1 might be excellent potential drug targets for NSCLC patients.

\section{Disclosure}

The authors have no conflicts of interest with this work.

\section{References}

1. Siegel R, Naishadham D, Jemal A. Cancer statistics, 2012. CA Cancer J Clin. 2012;62:10-29.

2. Guo P, Huang ZL, Yu P, Li K. Trends in cancer mortality in China: an update. Ann Oncol. 2012;23:2755-2762.

3. Ramalingam S, Belani C. Systemic chemotherapy for advanced non-small cell lung cancer: recent advances and future directions. Oncologist. 2008;13(suppl 1):5-13.

4. Douville J, Beaulieu R, Balicki D. ALDH1 as a functional marker of cancer stem and progenitor cells. Stem Cells Dev. 2009;18:17-25.

5. Ma I, Allan AL. The role of human aldehyde dehydrogenase in normal and cancer stem cells. Stem Cell Rev. 2011;7:292-306.

6. Ehlers CL. Variations in ADH and ALDH in Southwest California Indians. Alcohol Res Health. 2007;30:14-17.

7. Vasiliou V, Thompson DC, Smith C, Fujita M, Chen Y. Aldehyde dehydrogenases: from eye crystallins to metabolic disease and cancer stem cells. Chem Biol Interact. 2013;202:2-10.

8. Muzio G, Maggiora M, Paiuzzi E, Oraldi M, Canuto RA. Aldehyde dehydrogenases and cell proliferation. Free Radic Biol Med. 2012;52: 735-746.

9. Pearce DJ, Taussig D, Simpson C, et al. Characterization of cells with a high aldehyde dehydrogenase activity from cord blood and acute myeloid leukemia samples. Stem Cells. 2005;23:752-760.

10. Ginestier C, Hur MH, Charafe-Jauffret E, et al. ALDH1 is a marker of normal and malignant human mammary stem cells and a predictor of poor clinical outcome. Cell Stem Cell. 2007;1:555-567.

11. Balicki D. Moving forward in human mammary stem cell biology and breast cancer prognostication using ALDH1. Cell Stem Cell. 2007;1: 485-487.

12. Sreerama L, Sladek NE. Class 1 and class 3 aldehyde dehydrogenase levels in the human tumor cell lines currently used by the National Cancer Institute to screen for potentially useful antitumor agents. $A d v$ Exp Med Biol. 1997;414:81-94.

13. Patel M, Lu L, Zander DS, Sreerama L, Coco D, Moreb JS. ALDH1A1 and ALDH3A1 expression in lung cancers: correlation with histologic type and potential precursors. Lung Cancer. 2008;59:340-349.

14. Jiang F, Qiu Q, Khanna A, et al. Aldehyde dehydrogenase 1 is a tumor stem cell-associated marker in lung cancer. Mol Cancer Res. 2009;7: $330-338$.

15. Györffy B, Lanczky A, Eklund AC, et al. An online survival analysis tool to rapidly assess the effect of 22,277 genes on breast cancer prognosis using microarray data of 1,809 patients. Breast Cancer Res Treat. 2010; 123:725-731.

16. Győrffy B, Benke Z, Lánczky A, et al. RecurrenceOnline: an online analysis tool to determine breast cancer recurrence and hormone receptor status using microarray data. Breast Cancer Res Treat. 2012;132: $1025-1034$

17. Gyorffy B, Surowiak P, Budczies J, Lanczky A. Online survival analysis software to assess the prognostic value of biomarkers using transcriptomic data in non-small-cell lung cancer. PLoS One. 2013;8:e82241.
18. Liu M, Wang G, Gomez-Fernandez CR, Guo S. GREB1 functions as a growth promoter and is modulated by IL6/STAT3 in breast cancer. PLoS One. 2012;7:e46410.

19. Tilghman SL, Townley I, Zhong Q, et al. Proteomic signatures of acquired letrozole resistance in breast cancer: suppressed estrogen signaling and increased cell motility and invasiveness. Mol Cell Proteomics. 2013;12:2440-2455.

20. Zhou C, Zhong Q, Rhodes LV, et al. Proteomic analysis of acquired tamoxifen resistance in MCF-7 cells reveals expression signatures associated with enhanced migration. Breast Cancer Res. 2012;14:R45.

21. Maciejczyk A, Szelachowska J, Czapiga B, et al. Elevated BUBR1 expression is associated with poor survival in early breast cancer patients: 15-year follow-up analysis. J Histochem Cytochem. 2013;61: 330-339.

22. Maciejczyk A, Łacko A, Ekiert M, et al. Elevated nuclear S100P expression is associated with poor survival in early breast cancer patients. Histol Histopathol. 2013;28:513-524.

23. Maciejczyk A, Jagoda E, Wysocka T, et al. ABCC2 (MRP2, cMOAT) localized in the nuclear envelope of breast carcinoma cells correlates with poor clinical outcome. Pathol Oncol Res. 2012;18:331-342.

24. Adam MA. New prognostic factors in breast cancer. Adv Clin Exp Med. 2013;22:5-15.

25. Ivanova L, Zandberga E, Silina K, et al. Prognostic relevance of carbonic anhydrase IX expression is distinct in various subtypes of breast cancer and its silencing suppresses self-renewal capacity of breast cancer cells. Cancer Chemother Pharmacol. 2015;75:235-246.

26. Wu S, Xue W, Huang X, et al. Distinct prognostic values of ALDH1 isoenzymes in breast cancer. Tumour Biol. 2015;13:13.

27. Ortega CE, Seidner Y, Dominguez I. Mining CK2 in cancer. PLoS One. 2014;9:e115609.

28. Gyorffy B, Lanczky A, Szallasi Z. Implementing an online tool for genome-wide validation of survival-associated biomarkers in ovariancancer using microarray data from 1,287 patients. Endocr Relat Cancer. 2012;19:197-208.

29. Guo S, Liu M, Wang G, Torroella-Kouri M, Gonzalez-Perez RR. Oncogenic role and therapeutic target of leptin signaling in breast cancer and cancer stem cells. Biochim Biophys Acta. 2012;1825:207-222.

30. Reya T, Morrison SJ, Clarke MF, Weissman IL. Stem cells, cancer, and cancer stem cells. Nature. 2001;414:105-111.

31. Pang LY, Argyle DJ. Using naturally occurring tumours in dogs and cats to study telomerase and cancer stem cell biology. Biochim Biophys Acta. 2009;1792:380-391.

32. Kakarala M, Wicha MS. Implications of the cancer stem-cell hypothesis for breast cancer prevention and therapy. J Clin Oncol. 2008;26: $2813-2820$

33. Jordan CT, Guzman ML, Noble M. Cancer stem cells. NEnglJMed. 2006; 355:1253-1261.

34. Clarke MF. Self-renewal and solid-tumor stem cells. Biol Blood Marrow Transplant. 2005;11:14-16.

35. Clevers $\mathrm{H}$. The cancer stem cell: premises, promises and challenges. Nat Med. 2011;17:313-319.

36. Vasiliou V, Pappa A, Petersen DR. Role of aldehyde dehydrogenases in endogenous and xenobiotic metabolism. Chem Biol Interact. 2000;129: $1-19$.

37. Vasiliou V, Nebert DW. Analysis and update of the human aldehyde dehydrogenase (ALDH) gene family. Hum Genomics. 2005;2:138-143.

38. Burger PE, Gupta R, Xiong X, et al. High aldehyde dehydrogenase activity: a novel functional marker of murine prostate stem/progenitor cells. Stem Cells. 2009;27:2220-2228.

39. Chute JP, Muramoto GG, Whitesides J, et al. Inhibition of aldehyde dehydrogenase and retinoid signaling induces the expansion of human hematopoietic stem cells. Proc Natl Acad Sci U S A. 2006;103:11707-11712.

40. Zenke $\mathrm{Y}$, Ishii G, Ohe $\mathrm{Y}$, et al. Aldehyde dehydrogenase 1 expression in cancer cells could have prognostic value for patients with non-small cell lung cancer who are treated with neoadjuvant therapy: identification of prognostic microenvironmental factors after chemoradiation. Pathol Int. 2013;63:599-606. 
41. Dimou A, Neumeister V, Agarwal S, Anagnostou V, Syrigos K, Rimm DL. Measurement of aldehyde dehydrogenase 1 expression defines a group with better prognosis in patients with non-small cell lung cancer. $\mathrm{Am}$ J Pathol. 2012;181:1436-1442.

42. Krupenko NI, Dubard ME, Strickland KC, Moxley KM, Oleinik NV, Krupenko SA. ALDH1L2 is the mitochondrial homolog of 10-formyltetrahydrofolate dehydrogenase. J Biol Chem. 2010;285: 23056-23063.

43. Mieog JS, de Kruijf EM, Bastiaannet E, et al. Age determines the prognostic role of the cancer stem cell marker aldehyde dehydrogenase-1 in breast cancer. BMC Cancer. 2012;12:42.

44. Neumeister V, Agarwal S, Bordeaux J, Camp RL, Rimm DL. In situ identification of putative cancer stem cells by multiplexing ALDH1, CD44, and cytokeratin identifies breast cancer patients with poor prognosis. Am J Pathol. 2010;176:2131-2138.

45. Xu SL, Zeng DZ, Dong WG, et al. Distinct patterns of ALDH1A1 expression predict metastasis and poor outcome of colorectal carcinoma. Int J Clin Exp Pathol. 2014;7:2976-2986.

46. Yang L, Ren Y, Yu X, et al. ALDH1A1 defines invasive cancer stem-like cells and predicts poor prognosis in patients with esophageal squamous cell carcinoma. Mod Pathol. 2014;27:775-783.

47. Wang K, Chen X, Zhan Y, et al. Increased expression of ALDH1A1 protein is associated with poor prognosis in clear cell renal cell carcinoma. Med Oncol. 2013;30:574
48. Li XS, Xu Q, Fu XY, Luo WS. ALDH1A1 overexpression is associated with the progression and prognosis in gastric cancer. BMC Cancer. 2014; $14: 705$.

49. Xu J, Müller S, Nannapaneni S, et al. Comparison of quantum dot technology with conventional immunohistochemistry in examining aldehyde dehydrogenase $1 \mathrm{~A} 1$ as a potential biomarker for lymph node metastasis of head and neck cancer. Eur J Cancer. 2012;48:1682-1691.

50. Keymoosi H, Gheytanchi E, Asgari M, Shariftabrizi A, Madjd Z. ALDH1 in combination with CD44 as putative cancer stem cell markers are correlated with poor prognosis in urothelial carcinoma of the urinary bladder. Asian Pac J Cancer Prev. 2014;15:2013-2020.

51. Adam SA, Schnell O, Pöschl J, et al. ALDH1A1 is a marker of astrocytic differentiation during brain development and correlates with better survival in glioblastoma patients. Brain Pathol. 2012;22:788-797.

52. Moreb JS, Ucar D, Han S, et al. The enzymatic activity of human aldehyde dehydrogenases $1 \mathrm{~A} 2$ and 2 (ALDH1A2 and ALDH2) is detected by Aldefluor, inhibited by diethylaminobenzaldehyde and has significant effects on cell proliferation and drug resistance. Chem Biol Interact. 2012; 195:52-60.

53. Shao C, Sullivan JP, Girard L, et al. Essential role of aldehyde dehydrogenase 1A3 for the maintenance of non-small cell lung cancer stem cells is associated with the STAT3 pathway. Clin Cancer Res. 2014;20: 4154-4166.
Drug Design, Development and Therapy

\section{Publish your work in this journal}

Drug Design, Development and Therapy is an international, peerreviewed open-access journal that spans the spectrum of drug design and development through to clinical applications. Clinical outcomes, patient safety, and programs for the development and effective, safe, and sustained use of medicines are a feature of the journal, which

\section{Dovepress}

has also been accepted for indexing on PubMed Central. The manuscript management system is completely online and includes a very quick and fair peer-review system, which is all easy to use. Visit http://www.dovepress.com/testimonials.php to read real quotes from published authors.

Submit your manuscript here: http://www.dovepress.com/drug-design-development-and-therapy-journal 